\title{
Controle químico da Cercosporiose, Mancha-Branca e dos Grãos Ardidos em milho ${ }^{1}$
}

\author{
André Humberto Brito ${ }^{2}$, Renzo Garcia Von Pinho², José Luiz de Andrade Rezende Pereira ${ }^{2}$, Marcio Balestre ${ }^{2}$
}

\section{RESUMO}

Este trabalho foi realizado com o objetivo de avaliar os efeitos da aplicação de fungicida, no controle da Cercosporiose e da Mancha-Branca do milho, e suas consequências na produtividade de grãos e na incidência de grãos ardidos, além de estabelecer a relação existente entre a produtividade de grãos e a severidade dessas doenças. Dois experimentos distintos (com Azoxystrobina + Cyproconazole e tratamento controle) foram conduzidos em três locais, no ano agrícola de 2007/2008. Utilizaram-se 12 híbridos comerciais de milho, que foram avaliados em delineamento de blocos casualizados, com três repetições. Foram realizadas cinco avaliações da severidade das doenças Cercosporiose e Mancha-Branca, por meio de escala de notas, variando de 1 (altamente resistente) a 9 (altamente susceptível). Estimou-se a área abaixo da curva de progresso da doença (AACPD). A aplicação de fungicida é eficiente no controle de doenças foliares e na redução da incidência de grãos ardidos, além de proporcionar $12 \%$ de aumento na produtividade de grãos, em relação à do tratamento controle. As doenças foliares Cercosporiose e Mancha-Branca reduzem a produtividade de grãos de milho e essa redução é maior quando as doenças ocorrem mais precocemente. A Cercosporiose provoca maior redução na produtividade de grãos, quando comparada com a Mancha-Branca.

Palavras-chave: Azoxystrobina, Cyproconazole, Cercoporiose, mancha branca.

\section{ABSTRACT}

\section{Chemical control of gray leaf spot, white spot and rot grain in maize}

This work was carried out in order to evaluate the effects of fungicides on the control of maize gray leaf spot and maize white spot and its implications on the grain yield and rot grain, as well as to establish the relationship between grain yield and disease severity. Twelve commercial single cross hybrids were evaluated in a randomized block design with three repetitions. Five evaluations of disease severity (maize white spot and maize gray leaf spot) were performed using scale-visual symptoms, with scores ranging from 1 (highly resistant) to 9 (highly susceptible). In addition, the area under the disease progress curve (AUDPC) was estimated. Fungicide application is effective in the control of maize leaf diseases, and the experiments without control of the diseases had grain yield lower than that of the experiments with control, with a reduction of 1.2 t.ha $^{-1}(12.3 \%)$ on average. The fungicide application had a positive effect in the control of rot grains, with a reduction of $2.6 \%$ on average. Maize gray leaf spot and maize white spot reduce the maize grain yield and this reduction is greater when diseases occur earlier. Gray leaf spot causes a greater reduction in grain yield compared with white spot.

Key words: Azoxystrobina, Cyproconazole, Maize gray leaf spot, maize white spot.

\footnotetext{
Recebido para publicação em 06/04/2011 e aprovado em 18/04/2013.

${ }^{1}$ Parte do trabalho da Tese de Doutorado do primeiro autor.

${ }^{2}$ Engenheiros-Agrônomos, Doutores. Departamento de Agricultura, Universidade Federal de Lavras, Caixa Postal 37, 200-000, Lavras, Minas Gerais, Brasil. AHBrito@ dow.com; renzo@ufla.br; jlarpufla@yahoo.com.br (autor correspondente); marciobalestre@hotmail.com
} 


\section{INTRODUÇÃO}

A exposição da cultura do milho aos mais variados estresses bióticos e abióticos dificulta a exploração do máximo potencial genético para a produtividade de grãos, qualquer que seja o sistema de produção adotado. Por ser uma cultura cujo cultivo tem ampla abrangência geográfica, desenvolvendo-se nas mais diversas condições edafoclimáticas, é comum a ocorrência de elevado número de doenças. Assim, dezenas de doenças já foram identificadas na cultura de milho, no Brasil, causando perdas significativas (Pozar et al., 2009). Essas perdas, associadas, principalmente, às doenças foliares e à incidência de podridões de grãos, têm causado ampla discussão sobre estratégias de manejo que visem ao desenvolvimento de um programa que permita controlar as doenças de forma sustentável, principalmente no que diz respeito ao controle químico e genético.

Dentre as doenças, a Cercosporiose, cujo agente etiológico é o fungo Cercospora zeaemaydis, é, atualmente, uma das principais doenças foliares da cultura do milho, no Brasil, tanto por danos causados, como por sua ampla distribuição, sendo encontrada em todas as regiões produtoras (Brito et al., 2008). A partir do ano 2000, a doença, de ocorrência endêmica na forma de pequenas e esparsas lesões foliares, começou a assumir proporções epidêmicas em várias regiões do país (Juliatti et al., 2004). Essa doença foi responsável pela descontinuidade do uso de vários híbridos comerciais susceptíveis, de alto potencial produtivo, que chegaram a atingir níveis de redução de produtividade de grãos de até 40\% (Brandão, 2002; Souza, 2005; Brito et al., 2007).

Com relação ao controle químico da doença, em vários trabalhos houve relatos da eficácia de fungicidas dos grupos triazóis (triazóis + estrobilurinas) na produção do milho, com a crescente redução na severidade da doença (Juliatti et al., 2004; Brito et al., 2007; Costa, 2007).

Outra doença foliar de grande importância, no Brasil, é a Mancha Branca, cujo agente etiológico é o fungo Phaeosphaeria maydis (Fernandes \& Oliveira, 1997), em associação com a bactéria Pantoea ananas (PaccolaMeirelles et al., 2001). Segundo Fernandes \& Oliveira (1997), os híbridos susceptíveis à Mancha-Branca podem chegar a apresentar perdas de até $60 \%$ na produção.

Segundo Pereira et al. (2005), os fungicidas dos grupos químicos das estrobilurinas e ditiocarbatos apresentaram controle eficiente da doença. No entanto, Juliatti et al. (2004) verificaram a ineficiência dos fungicidas triazóis no controle da Mancha Branca. Essas doenças foliares, associadas a condições climáticas favoráveis e à susceptibilidade dos híbridos, proporcionaram também o aumento na incidência de podridões de grãos e espigas, que provocam o aparecimento de grãos ardidos. Nas duas úl- timas safras agrícolas, a incidência dessas doenças foi significativa, provocando redução na produção e perdas na qualidade do produto (Mendes, 2009). Os fungos mais frequentemente detectados e associados ao complexo grãos ardidos são Fusarium verticilioides, Fusarium graminearum Gibberellazeae, Diplodia maydise, Diplodia macrospora.

Recentemente, foi relatada a eficácia da utilização de fungicidas no controle de grãos ardidos. Segundo Juliatti et al. (2007), a aplicação, por via foliar, de fungicidas triazóis e estrobirulinas (Piraclostrobin + Epoxiconazole, Azoxystrobin + Ciproconazole e Azoxystrobin), resultou em menor incidência de grãos ardidos no milho. O uso de azoxystrobina + cyproconazole, em aplicação foliar no prépendoamento, possibilitou reduzir a incidência de grãos ardidos em $5,12 \%$, além de aumentar a produtividade em $12 \%$, de diferentes híbridos cultivados sob alta severidade de doenças, com e sem aplicação de fungicidas (Brito et al., 2008).

Este trabalho foi realizado com o fim de avaliar os efeitos da aplicação de fungicidas nas doenças foliares Cercosporiose e Mancha-Branca do milho, na produtividade de grãos e na incidência de grãos ardidos e, também, de estabelecer a relação existente entre a produtividade de grãos e a severidade dessas doenças.

\section{MATERIAL E MÉTODOS}

Os experimentos foram realizados, em três locais no Estado de Minas Gerais, na safra agrícola 2007/2008: na área experimental do Departamento de Agricultura, da Universidade Federal de Lavras, em Lavras; na fazenda experimental da Fundação de Ensino Superior de Passos (FESP/UEMG), localizada no município de Passos; e na área experimental do Centro Universitário de Patos de Minas (UNIPAM), em Patos de Minas.

Em todos os locais, a condução dos experimentos deuse em período de ocorrência de temperaturas, intensidade e distribuição de chuvas favoráveis ao cultivo do milho e ao progresso das doenças. A instalação dos experimentos nos três locais foi realizada no sistema de plantio convencional, em áreas onde se pratica a sucessão de culturas, com o plantio de milho após milho, resultando em grande fonte de inóculos de agentes etiológicos, necrotróficos, de doenças foliares e de grãos ardidos.

Foram utilizados 12 híbridos simples, com diferentes características, provenientes de diferentes empresas sementeiras do Brasil (Tabela 1), com e sem o tratamento com fungicidas. Os híbridos foram selecionados de acordo com informações das empresas produtoras com relação ao grau de resistência à Mancha-Branca e à Cercosporiose e à utilização pelos agricultores, nos locais de condução dos experimentos. 
O delineamento foi em blocos casualizados, com três repetições. As parcelas foram constituídas de quatro fileiras de 5,0 m de comprimento, sendo as duas fileiras centrais consideradas como úteis. $\mathrm{O}$ espaçamento entre fileiras foi de $0,8 \mathrm{~m} \mathrm{e}$, a densidade, de cinco plantas por metro linear, após o desbaste.

$\mathrm{Na}$ semeadura, foram utilizados $450 \mathrm{~kg} \mathrm{ha}^{-1}$ da fórmula $8(\mathrm{~N}): 28\left(\mathrm{P}_{2} \mathrm{O}_{5}\right): 16\left(\mathrm{~K}_{2} \mathrm{O}\right)$. Em cobertura, foram aplicados $300 \mathrm{~kg} \mathrm{ha}^{-1}$ da fórmula $30(\mathrm{~N}): 00\left(\mathrm{P}_{2} \mathrm{O}_{5}\right): 20\left(\mathrm{~K}_{2} \mathrm{O}\right)$, no estádio de 4-5 folhas totalmente expandidas. Foram utilizados os mesmos tratos culturais para ambos os experimentos, nos três locais, com exceção da aplicação de fungicida. Nos experimentos em que foi feito o controle das doenças, foram utilizados fungicidas (Azoxystrobina + Cyproconazole), na dosagem de $0,301 \mathrm{ha}^{-1}+0,5 \%$ do óleo mineral, em duas aplicações, sendo uma no estádio de dez folhas totalmente expandidas e, a outra, no prépendoamento. A aplicação foi realizada utilizando-se um volume de calda de $200 \mathrm{~L} \mathrm{ha}^{-1}$, o bico tipo leque e equipamento costal de pulverização de $20 \mathrm{~L}$.

O início do progresso das doenças ocorreu por infecção natural. Para aumentar o potencial de inóculo das doenças, em torno das áreas experimentais, foram plantadas linhas de bordadura com o híbrido AG 9020, susceptível às doenças em estudo.

Avaliou-se, de forma isolada, a severidade da Cercosporiose (Cercospora zeae-maydis) e da ManchaBranca (Pantoea ananas/Phaeosphaeria maydis). Para isso, foram utilizados os dados de severidade na parcela (notas), considerando-se a parcela como um todo, obtidos com o auxílio da escala diagramática de Pinho et al. (2001). As notas de severidade de cada doença, nesta escala, variam de um a nove, de acordo com a percentagem de área foliar afetada, em que: $1(0 \%), 2(1 \%), 3(>1 \%$ $\mathrm{e} \leq 10 \%), 4(>10 \% \mathrm{e} \leq 20 \%), 5(>20 \% \mathrm{e} \leq 30 \%), 6(>30 \%$ $\mathrm{e} \leq 40 \%), 7(>40 \% \mathrm{e} \leq 60 \%), 8(>60 \%$ e $\leq 80 \%)$ e $9(>80 \%)$, sendo 1 altamente resistente, 2 e 3 resistentes, 4 medianamente resistente, 5 e 6 medianamente susceptível, 7 e 8 susceptível e 9 altamente susceptível. Foram realizadas cinco avaliações, em intervalos de sete dias, a partir de 80 dias após a emergência das plantas. Esses dados foram utilizados para calcular a área abaixo da curva de progresso da doença (AACPD), conforme Shanner \& Finney (1977).

Para determinar a produção de grãos por hectare, foi realizada a colheita manual das espigas das duas fileiras centrais da parcela. As espigas foram debulhadas, os grãos pesados e determinado o teor de água. Os dados de produtividade de grãos foram corrigidos para um teor de $13 \%$ de umidade e expressos em $\mathrm{kg} \mathrm{ha}^{-1}$.

A incidência (percentagem) de grãos ardidos foi determinada conforme procedimento proposto na Portaria $\mathrm{n}^{\mathrm{o}} 11$ do Ministério da Agricultura, de 12/04/96 (Brasil, 1996). O método consiste na separação visual e na determinação da percentagem de grãos com sintomas de descoloração em mais de um quarto da sua superfície total, a partir de uma amostra aleatória de $250 \mathrm{~g}$ de grãos por parcela.

Com relação às avaliações de grãos ardidos, é importante ressaltar que, em todos os experimentos, e em todos os locais, as espigas foram colhidas quando o teor de água dos grãos encontrava-se entre 18 e $22 \%$. Isso foi feito com o objetivo de minimizar os efeitos do teor de água dos grãos na incidência de grãos ardidos, permitindo a comparação entre os dados obtidos.

Os dados de todas as variáveis foram submetidos, inicialmente, à análise de variância individual em cada local separadamente, em esquema fatorial Híbridos (12) x Controle da doença (com e sem tratamento fungicida). A princípio, foram realizados os testes de aditividade dos efeitos do modelo e a normalidade dos erros. Não havendo restrição a essas pressuposições, foram realizadas as análises de variâncias individuais. De posse dos resulta-

Tabela 1. Características dos híbridos de milho utilizados nos experimentos

\begin{tabular}{|c|c|c|c|c|c|}
\hline Híbridos & Ciclo & Tipo de grão & Mancha-Branca* & Cercosporiose* & Podridão de grãos* \\
\hline DKB 390 & Precoce & Semiduro & $\mathrm{R}$ & $\mathrm{R}$ & $\mathrm{S}$ \\
\hline DKB 177 & Precoce & Semiduro & $\mathrm{R}$ & $\mathrm{R}$ & MR \\
\hline AG 7010 & Precoce & Semiduro & $\mathrm{R}$ & $\mathrm{R}$ & MR \\
\hline AG 7088 & Semiprecoce & Semiduro & $\mathrm{R}$ & $\mathrm{R}$ & MR \\
\hline AG 8088 & Precoce & Duro & $\mathrm{R}$ & MR & $\mathrm{S}$ \\
\hline Impacto & Precoce & Duro & MR & MR & $\mathrm{R}$ \\
\hline 2B707 & Precoce & Semiduro & MR & MR & $\mathrm{R}$ \\
\hline 2B587 & Precoce & Semidentado & MR & MR & $\mathrm{R}$ \\
\hline P30F53 & Precoce & Semiduro & MS & MS & $\mathrm{S}$ \\
\hline P30F44 & Precoce & Semiduro & $\mathrm{S}$ & S & $\mathrm{R}$ \\
\hline P30K64 & Semiprecoce & Semiduro & $\mathrm{S}$ & MS & MS \\
\hline AG 8021 & Precoce & Semidentado & MR & $\mathrm{S}$ & $\mathrm{S}$ \\
\hline
\end{tabular}

*Resistência às doenças Mancha-Branca (Pantoea ananas/Phaeosphaeria maydis), Cercosporiose (Cercospora zeae-maydis) e podridão de grãos, sendo $\mathrm{S}=$ susceptível, $\mathrm{MR}=$ moderadamente resistente, $\mathrm{MS}=$ moderadamente susceptível e $\mathrm{R}=$ resistente, de acordo com informações das empresas produtoras de sementes. 
dos dessas análises, também foi verificada a pressuposição de homogeneidade de variâncias pelo teste de Hartley, citado por Gomes (1990), o qual se baseia na divisão do maior quadrado médio do resíduo pelo menor quadrado médio do resíduo das análises individuais. Sendo o valor resultante inferior a sete, infere-se homogeneidade de variâncias, o que possibilita a análise conjunta dos experimentos. Assim, os dados de cada variável, obtidos em cada local, foram submetidos a uma análise de variância conjunta, envolvendo todos os experimentos conduzidos nos três locais.

Foi estimado o coeficiente de regressão linear $\left(b_{1}\right)$ entre severidade de doença (média das notas), variável independente (x), com a produtividade de grãos, variável dependente (y), por doença e em cada época de avaliação e local (Stell \& Torrie, 1980). Também foram obtidas as estimativas das correlações parciais, considerando-se como variável independente (x) a AACPD e, como variável dependente (y), a produtividade de grãos, utilizandose as expressões apresentadas por Cruz et al. (2004).

As análises foram feitas nos programas Statistical Analysis System (SAS Institute Inc., 1993) e Sisvar (Ferreira, 2000). As médias dos híbridos foram agrupadas pelo teste de Scott-Knott ( $\mathrm{p} \leq 0,05)$.

\section{RESULTADOS E DISCUSSÃO}

Nos experimentos sem aplicação de fungicidas, a severidade das doenças foliares Cercosporiose (Cercospora zeaemaydis) e Mancha-Branca (Pantoea ananas/ Phaeosphaeria maydis), nos três locais de avaliação, foi suficiente para reduzir a produtividade de grãos (Tabelas 2 e 3). Ressalta-se que, em todos os experimentos sem aplicação de fungicida, apesar de terem ocorrido outras doenças, como, por exemplo, a mancha-de-diplodia (Stenocarpella macrospora), em Lavras e em Patos de Minas e ferrugem (Puccinia polysora), em Passos, a severidade foi baixa, em todos os locais.

Em relação à severidade das doenças ocorridas com aplicação de fungicida, em todos os locais, esses valores foram baixos, com notas sempre iguais ou inferiores a três, ou seja, sempre menor que dez por cento de área foliar lesionada. Isso mostra a eficiência do fungicida utilizado para controlar as doenças, permitindo inferir que, nas parcelas com controle químico das doenças, os híbridos puderam expressar melhor seu potencial genético para a produção de grãos. Brito et al. (2007) também verificaram que, nas parcelas com controle químico, a severidade da Cercosporiose foi sempre inferior a $0,5 \%$.

Pela análise conjunta, envolvendo os três locais, a produtividade de grãos foi influenciada pelo efeito de híbridos, fungicida, locais e interações (híbridos x fungicida e híbridos $\mathrm{x}$ locais $(\mathrm{p} \leq 0,01)$ ). A precisão experimental, avaliada pelo coeficiente de variação, foi considerada boa, com CV igual a 8,32\%.

Houve variação significativa na produtividade de grãos dos híbridos, porém essas produtividades não foram coincidentes nos diferentes experimentos e locais. No experimento com fungicida, os híbridos apresentaram desempenhos semelhantes, com exceção dos híbridos 2B587 e 2B707, superiores aos demais (Tabela 3). Para o experimento sem fungicida, novamente, os híbridos 2B587 e 2B707 e o híbrido DKB177 foram superiores aos demais.

Dentre os experimentos com e sem fungicida, como era esperado, os híbridos nos experimentos sem controle

Tabela 2. Resultados médios de produtividade de grãos - PG ( $\left(\right.$ ha $\left.^{-1}\right)$ - e grãos ardidos - GA (\%) - dos híbridos de milho avaliados em experimentos com e sem aplicação de fungicida, considerando os três locais de condução dos experimentos

\begin{tabular}{|c|c|c|c|c|}
\hline \multirow{2}{*}{ Híbridos } & \multicolumn{2}{|c|}{ PG $\left(\mathrm{t} \mathrm{ha}^{-1}\right)$} & \multicolumn{2}{|c|}{ GA (\%) } \\
\hline & Com & Sem & Com & Sem \\
\hline 2B587 & $10,42 \mathrm{bB}$ & $9,61 \mathrm{dA}$ & $3,26 \mathrm{bA}$ & $5,43 \mathrm{cB}$ \\
\hline 2B707 & $10,97 \mathrm{bB}$ & $9,89 \mathrm{dA}$ & $2,78 \mathrm{aA}$ & $3,13 \mathrm{aA}$ \\
\hline 30F44 & $9,06 \mathrm{aB}$ & $7,42 \mathrm{aA}$ & $2,09 \mathrm{aA}$ & $3,53 \mathrm{aB}$ \\
\hline 30F53 & $9,59 \mathrm{aB}$ & $7,62 \mathrm{aA}$ & $4,17 \mathrm{cA}$ & 7,38 eB \\
\hline 30K64 & $9,84 \mathrm{aB}$ & $8,39 \mathrm{bA}$ & $2,50 \mathrm{aA}$ & $5,05 \mathrm{cB}$ \\
\hline AG 7010 & $9,40 \mathrm{aA}$ & $8,86 \mathrm{cA}$ & $5,69 \mathrm{dA}$ & $9,48 \mathrm{fB}$ \\
\hline AG 7088 & $9,61 \mathrm{aA}$ & $9,11 \mathrm{cA}$ & $4,17 \mathrm{dA}$ & $6,08 \mathrm{~dB}$ \\
\hline AG 8021 & $9,55 \mathrm{aB}$ & $7,41 \mathrm{aA}$ & $2,12 \mathrm{aA}$ & $3,76 \mathrm{aB}$ \\
\hline AG 8088 & $9,93 \mathrm{aB}$ & $8,38 \mathrm{bA}$ & $3,59 \mathrm{bA}$ & $10,51 \mathrm{gB}$ \\
\hline DKB 177 & $9,93 \mathrm{aB}$ & $9,47 \mathrm{dA}$ & $2,70 \mathrm{aA}$ & $4,08 \mathrm{bB}$ \\
\hline DKB 390 & $10,03 \mathrm{aB}$ & $8,95 \mathrm{cA}$ & $5,24 \mathrm{dA}$ & $9,34 \mathrm{fB}$ \\
\hline Impacto & $9,79 \mathrm{aB}$ & $8,77 \mathrm{cA}$ & $2,40 \mathrm{aA}$ & $4,36 \mathrm{bB}$ \\
\hline Média & $9,87 \mathrm{~B}$ & $8,66 \mathrm{~A}$ & $3,39 \mathrm{~A}$ & $6,01 \mathrm{~B}$ \\
\hline $\mathrm{CV}(\%)$ & \multicolumn{2}{|c|}{8,32} & \multicolumn{2}{|c|}{17,60} \\
\hline
\end{tabular}

Médias seguidas de letras distintas minúsculas na coluna diferem, entre si, pelo teste de Scott-Knott (p d" 0,05); médias seguidas de letras distintas maiúsculas na linha diferem, entre si, pelo teste de $\mathrm{F}(\mathrm{p} \leq 0,01)$. 
das doenças apresentaram produtividades de grãos inferiores, quando comparados ao desempenho deles nos experimentos com controle, com exceção dos híbridos mais resistentes às doenças (AG7010 e AG7088), com comportamentos semelhantes (Tabela 3). Em média, essa diferença foi de $1,21 \mathrm{t} \mathrm{ha}^{-1}$, ou seja, 12,3\%. Isso mostra a eficiência do fungicida utilizado para o controle das doenças foliares, além do efeito das doenças na redução da produtividade de grãos. O efeito da aplicação de fungicidas na produtividade de grãos de milho já foi descrito por vários autores (Juliatti et al., 2004; Brito et al., 2007; Costa, 2007).

Com relação aos locais de condução dos experimentos, houve diferenciação na produtividade de grãos entre os híbridos, ou seja, seus desempenhos não foram semelhantes, nos três locais (Tabela 3). Os experimentos conduzidos em Lavras, independentemente do controle, ou não, das doenças, apresentaram produtividades de grãos superiores às obtidas nos outros locais. A produtividade média, considerando-se os três locais, foi de $9,25 \mathrm{t}$ $\mathrm{ha}^{-1}$, com valores de 10,36 tha ${ }^{-1}$, em Lavras; 9,04 tha- ${ }^{-1}$ em Passos e 8,35 tha-1, em Patos de Minas.

Um dos fatores que explicam a maior produtividade de grãos, em Lavras, está relacionado com a menor severidade da Cercosporiose, a qual reduz a produtividade de grãos. Brito et al. (2007) quantificaram os danos causados pela Cercosporiose na região sul de Minas Gerais, e observaram valores que variaram de 16 a 27\%, para híbridos susceptíveis à doença. Os mesmos autores concluíram que os níveis de danos causados pela Cercosporiose no milho variam entre as épocas de semeadura e entre os híbridos avaliados, com diferentes níveis de resistência, sendo, em média, de 13,3\%.
Verificou-se, pela análise conjunta, para os dados de grãos ardidos, envolvendo os três locais e os dois tratamentos, com e sem aplicação de fungicida, que ocorreram diferenças significativas $(\mathrm{p} \leq 0,01)$ para todas as fontes de variação. A precisão experimental, avaliada pelo coeficiente de variação, foi considerada boa, com CV igual a $17,6 \%$.

Nos experimentos com utilização de fungicida, os híbridos não apresentaram desempenhos semelhantes, tendo os híbridos AG7010, AG7088 e DKB390 obtido maiores percentagens de grãos ardidos (Tabela 3). Em média, os híbridos apresentaram baixa incidência de grãos ardidos, com valor de $3,39 \%$. No experimento sem aplicação de fungicida, o híbrido que apresentou a maior incidência de grãos ardidos foi o AG8088 (10,51\%), tendo sido os híbridos $2 \mathrm{~B} 707$ (3,13\%), 30F44 (3,53\%) e AG8021 (3,76\%) os que mostraram maior tolerância.

Pela comparação dos dados obtidos nos experimentos com e sem fungicida, verifica-se que os híbridos nos experimentos sem controle das doenças apresentaram maior incidência de grãos ardidos, com exceção do híbrido 2B707, que mostrou comportamentos semelhantes nas duas situações (Tabela 3). Em média, houve redução de $2,6 \%$ na incidência de grãos ardidos, quando realizada a aplicação do fungicida. Isso evidencia que o uso de fungicida na cultura do milho possibilita a redução da incidência de grãos ardidos. Esses resultados corroboram os obtidos por Juliatti et al. (2007), segundo os quais a aplicação de fungicidas triazóis e estrobirulinas (Piraclostrobin + Epoxiconazole, azoxystrobin + cyproconazole e Azoxystrobin), por via foliar, resultou em uma menor incidência de grãos ardidos no milho. $\mathrm{O}$ uso

Tabela 3. Resultados médios de produtividade de grãos - PG (t ha $\left.{ }^{-1}\right)$ - e grãos ardidos - GA (\%) - de híbridos de milho avaliados em três locais de condução dos experimentos, considerando os experimentos com e sem aplicação de fungicida

\begin{tabular}{|c|c|c|c|c|c|c|}
\hline \multirow{2}{*}{ Híbridos } & \multicolumn{3}{|c|}{ PG $\left(\right.$ t ha $\left.^{-1}\right)$} & \multicolumn{3}{|c|}{ GA (\%) } \\
\hline & Lavras & Passos & Patos & Lavras & Passos & Patos \\
\hline 2B587 & $11,06 \mathrm{cB}$ & $9,62 \mathrm{cA}$ & $9,36 \mathrm{cA}$ & $3,97 \mathrm{bB}$ & $1,60 \mathrm{aA}$ & $7,47 \mathrm{cC}$ \\
\hline 2B707 & $12,19 \mathrm{dC}$ & $10,13 \mathrm{cB}$ & $8,97 \mathrm{cA}$ & $2,57 \mathrm{aA}$ & $1,81 \mathrm{aA}$ & $4,48 \mathrm{bB}$ \\
\hline $30 \mathrm{~F} 44$ & $8,90 \mathrm{aB}$ & 7,50 aA & $8,31 \mathrm{cB}$ & $2,60 \mathrm{aA}$ & $1,86 \mathrm{aA}$ & $3,98 \mathrm{aB}$ \\
\hline 30F53 & $10,19 \mathrm{bB}$ & $7,82 \mathrm{aA}$ & $7,82 \mathrm{bA}$ & $6,91 \mathrm{cB}$ & $3,43 \mathrm{bA}$ & $6,99 \mathrm{cB}$ \\
\hline 30K64 & $9,80 \mathrm{bB}$ & $8,80 \mathrm{bA}$ & $8,74 \mathrm{cA}$ & $3,53 \mathrm{aA}$ & $3,26 \mathrm{bA}$ & $4,55 \mathrm{bB}$ \\
\hline AG 7010 & 9,76 bB & $9,24 \mathrm{bB}$ & $8,39 \mathrm{cA}$ & $4,81 \mathrm{bA}$ & $5,13 \mathrm{cA}$ & $12,81 \mathrm{fB}$ \\
\hline AG 7088 & $10,94 \mathrm{cC}$ & $9,14 \mathrm{bB}$ & $8,01 \mathrm{bA}$ & $3,09 \mathrm{aA}$ & $3,46 \mathrm{bA}$ & $8,83 \mathrm{~dB}$ \\
\hline AG 8021 & $10,09 \mathrm{cC}$ & $8,52 \mathrm{aB}$ & $6,83 \mathrm{aA}$ & $3,45 \mathrm{aB}$ & $1,71 \mathrm{aA}$ & $3,65 \mathrm{aB}$ \\
\hline AG 8088 & 9,82 bB & $9,09 \mathrm{bA}$ & $8,55 \mathrm{cA}$ & $7,46 \mathrm{cB}$ & $4,19 \mathrm{cA}$ & $9,50 \mathrm{dC}$ \\
\hline DKB 177 & $10,79 \mathrm{cB}$ & $9,15 \mathrm{bA}$ & $9,17 \mathrm{cA}$ & $3,37 \mathrm{aB}$ & $1,96 \mathrm{aA}$ & $4,86 \mathrm{bC}$ \\
\hline DKB 390 & $10,52 \mathrm{cC}$ & $9,58 \mathrm{cB}$ & $8,37 \mathrm{cA}$ & $6,49 \mathrm{cB}$ & $4,93 \mathrm{cA}$ & $10,46 \mathrm{eC}$ \\
\hline Impacto & $10,21 \mathrm{bB}$ & $9,95 \mathrm{cB}$ & $7,69 \mathrm{bA}$ & $2,84 \mathrm{aB}$ & $1,75 \mathrm{aA}$ & $5,55 \mathrm{bC}$ \\
\hline Média & $10,36 \mathrm{C}$ & $9,04 \mathrm{~B}$ & $8,35 \mathrm{~A}$ & $4,26 \mathrm{~B}$ & $2,92 \mathrm{~A}$ & $6,93 \mathrm{C}$ \\
\hline $\mathrm{CV}(\%)$ & & 8,32 & & & 17,60 & \\
\hline
\end{tabular}

Médias seguidas de mesmas letras minúsculas, na coluna, e maiúscula, na linha, pertencem ao mesmo agrupamento, pelo teste de Scott Knott, a 5\% de significância. 
do fungicida Priori Xtra (azoxystrobin + cyproconazole) também foi relatado por Brito et al. (2008), que avaliaram diferentes híbridos, cultivados em condições de alta pressão de doenças, com e sem aplicação do fungicida. Os autores concluíram que a aplicação do fungicida por via foliar possibilitou a redução da incidência de grãos ardidos de 5,12\%, além de um aumento, na produtividade líquida, de $12,4 \%$.

Considerando-se os três locais, verificou-se que os experimentos realizados em Patos de Minas apresentaram maior incidência de grãos ardidos $(6,93 \%)$, seguidos dos de Lavras $(4,26 \%)$ e dos de Passos $(2,92 \%)$.

As estimativas dos coeficientes de regressão linear $\left(b_{1}\right)$ entre a severidade de doença (média das notas), com a produtividade de grãos, nas diferentes épocas de avaliação e locais, são apresentadas na Tabela 4.

Considerando-se a Cercosporiose, os danos, em termos de produtividade de grãos ( $\mathrm{t} / \mathrm{ha}$ ), foram tanto maiores quanto mais precocemente ocorreu a avaliação, independentemente do local considerado. Observa-se que, com 80 dias, cada acréscimo de uma unidade na nota de severidade da doença acarretou redução de até 1,08 $\mathrm{t} \mathrm{ha}^{-1} \mathrm{e} 1,11 \mathrm{t}$ ha $^{-1}$, em Lavras e em Passos, respectivamente. Constatase, contudo, que, nessa primeira avaliação, as notas atribuídas ao patógeno ainda eram muito baixas. Entretanto, mesmo com essa pequena amplitude de variação, foram detectados efeitos expressivos na redução da produtividade. Isso ocorreu porque, quanto mais precocemente a planta é infectada, maior o dano causado (Tabela 4).

Esses resultados permitem inferir que, no caso da Cercosporiose, o material genético será tanto mais afetado quanto mais precocemente manifestar o sintoma da doença. Depreende-se, então, que as avaliações dessa doença devem ser iniciadas precocemente, tão logo comecem a se manifestar os sintomas. Nesse caso, as avaliações certamente seriam facilitadas, pois seriam mais precisas e com reflexo direto na produtividade. Avaliações dessa doença devem ser realizadas, também, em outras épocas, para que se possa estimar a taxa de progresso da doença e, assim, confirmar, ou não, a inferência a respeito da resistência precoce conferida aos híbridos. Brito et al. (2008) concluíram que a avaliação da Cercosporiose entre os 90 e 110 dias após a emergência das plantas é eficiente para discriminar o nível de resistência dos híbridos, além de fornecer resultados semelhantes àqueles obtidos com a AACPD.

Para a Mancha-Branca, também foi constatado que, quanto mais precoce a incidência, maior é o dano, considerando-se a produtividade de grãos. Observa-se que, com 80 dias, a estimativa de $b_{1}$ foi de $-0,60,-1,75$ e - 0,45 , para Lavras, Passos e Patos de Minas, respectivamente (Tabela 4). Isso indica uma redução, em média, de 0,6 t ha ${ }^{-1}$, em Lavras; 1,75 t ha ${ }^{-1}$, em Passos e 0,45 t ha-1, em Patos, por acréscimo de uma unidade na nota de severidade da doença. É preciso salientar que, na região de Passos, não se observou consistência nas estimativas de $b_{1}$, como as observadas para a Cercosporiose, pois, como já mencionado, a severidade dessa doença foi menor, comparada à dos outros dois locais (Tabela 4).

As estimativas das correlações parciais permitem inferir sobre o dano provocado por um dos patógenos, desconsiderando-se a ocorrência do outro. Portanto, neste experimento, elas foram úteis, pois, no campo, não foi possível conduzir experimentos em que ocorresse apenas uma das doenças. Na Tabela 5, estão apresentadas as estimativas das correlações parciais entre a AACPD e a produtividade de grãos, para cada local. Constata-se que as correlações envolvendo a Cercosporiose, desconsiderando-se o efeito da Mancha-Branca, apresentaram estimativas maiores, exceto em Lavras, onde a incidência de Cercosporiose, como já mencionado, foi menor. Constataram-se valores significativos e negativos para as correlações entre a produtividade de grãos e a AACPD da Cercosporiose, para Passos e Patos de Minas, ou seja, quanto maior a severidade da doença, menor será a produtividade. Já em Lavras, não se observou correlação significativa entre a produtividade de grãos e AACPD, para ambas as doenças (Tabela 5).

Tabela 4. Coeficientes de regressão linear $\left(b_{1}\right)$, envolvendo a produtividade de grãos $\left(t\right.$ ha $\left.{ }^{-1}\right)$ com a severidade média da Cercosporiose (CE) e da Mancha-Branca (MB), em cinco épocas de avaliação, realizadas em três locais de condução dos experimentos

\begin{tabular}{|c|c|c|c|c|c|c|c|c|c|c|}
\hline \multirow{3}{*}{$\begin{array}{l}\text { Locais } \\
\text { Severidade por local }\end{array}$} & \multicolumn{10}{|c|}{ Épocas de avaliação } \\
\hline & \multicolumn{2}{|c|}{80 dias } & \multicolumn{2}{|c|}{87 dias } & \multicolumn{2}{|c|}{94 dias } & \multicolumn{2}{|c|}{101 dias } & \multicolumn{2}{|c|}{108 dias } \\
\hline & $\mathbf{C E}$ & MB & $\mathbf{C E}$ & MB & $\mathbf{C E}$ & MB & $\mathbf{C E}$ & MB & $\mathbf{C E}$ & MB \\
\hline Lavras & $-1,08$ & $-0,60$ & $-0,53$ & $-0,36$ & $-0,45$ & $-0,36$ & $-0,32$ & $-0,26$ & $-0,25$ & $-0,15$ \\
\hline V.E.* & $1-3$ & $1-3$ & $1-3$ & $1-4$ & $1-4$ & $1-6$ & $1-5$ & $1-6$ & $1-7$ & $1-9$ \\
\hline Passos & $-1,11$ & $-1,75$ & $-0,85$ & $-1,86$ & $-0,73$ & $-1,44$ & $-0,60$ & $-0,78$ & $-0,52$ & $-0,69$ \\
\hline V.E. & $1-4$ & $1-3$ & $1-4$ & $1-3$ & $1-6$ & $1-3$ & $1-7$ & $1-4$ & $1-8$ & $1-5$ \\
\hline Patos de Minas & $-0,38$ & $-0,45$ & $-0,26$ & $-0,31$ & $-0,22$ & $-0,23$ & $-0,17$ & $-0,20$ & $-0,18$ & $-0,14$ \\
\hline V.E. & $1-4$ & $1-5$ & $1-6$ & $1-6$ & $1-7$ & $1-7$ & $1-8$ & $1-7$ & $1-8$ & $1-7$ \\
\hline
\end{tabular}

*V.E. = valores extremos (nota mínima observada - nota máxima observada) para a severidade da doença. 
Tabela 5. Coeficientes de correlação parcial (r) da área abaixo da curva de progresso da doença (AACPD) com a produtividade de grãos $\left(\mathrm{t} \mathrm{ha}^{-1}\right)$, considerando o efeito da Cercosporiose, desconsiderando a Mancha-Branca e vice-versa, em três locais

\begin{tabular}{lll}
\hline \multirow{2}{*}{$\begin{array}{l}\text { Produtividade } \\
\text { por local }\end{array}$} & \multicolumn{2}{c}{ AACPD } \\
\cline { 2 - 3 } & $\begin{array}{c}\text { Cercosporiose } \\
\text { (média) }^{\mathbf{1}}\end{array}$ & $\begin{array}{c}\text { Mancha-Branca } \\
\text { (média) }\end{array}$ \\
\hline Lavras & $-0,39(203,29)$ & $-0,41(568,41)$ \\
Passos & $-0,82^{* *}(498,83)$ & $-0,37(74,33)$ \\
Patos de Minas & $-0,54 * *(662,18)$ & $-0,46 * *(591,98)$ \\
\hline
\end{tabular}

${ }^{1}$ Média referente à área abaixo da curva de progresso da doença.

** Significativo, a $1 \%$ de probabilidade $\left(\mathrm{H}_{0}: \mathrm{r}=0\right)$.

\section{CONCLUSÕES}

A aplicação de fungicida é eficiente no controle de doenças foliares e proporciona maiores produtividades de grãos, em média, $12 \%$ superiores àquelas em que não se utilizou fungicida.

O uso de fungicida em aplicação foliar possibilita a redução da incidência de grãos ardidos.

As doenças foliares Cercosporiose e Mancha-Branca reduzem a produtividade de grãos de milho e essa redução é maior quando as doenças ocorrem precocemente.

A Cercosporiose provoca maior redução na produtividade de grãos, quando comparada com a ManchaBranca.

\section{REFERÊNCIAS}

Brandão AM (2002) Manejo da Cercosporiose (Cercosporazeaemaydis Tehon e Daniels) e da ferrugem comum do milho (Puccinia sorghi Schw.) pelo uso da resistência genética, fungicidas e épocas de aplicação. Dissertação de Mestrado. Universidade Federal de Uberlândia, Uberlândia. 169p.

Brasil (1996) Portaria $n^{\circ} 11$, de 12 de abril de 1996 Estabelece critérios complementares para classificação do milho. Diário Oficial da União, Brasília, n.72.

Brito AH, Pinho RG Von, Pozza EA, Pereira JLAR \& Faria Filho EM (2007) Efeito da Cercosporiose no rendimento de híbridos comerciais de milho. Fitopatologia Brasileira, 32:32-36.

Brito AH, Pinho RG Von, Souza Filho AX \& Altoé TF (2008) Avaliação da severidade da Cercosporiose e rendimento de grãos em híbridos comerciais de milho. Revista Brasileira de Milho e Sorgo, 7:19-31.

Costa FM (2007) Análise da curva de progresso temporal de doenças foliares na cultura do milho (Zea mays L.), sob a aplicação da mistura de fungicidas triazóis e estrobirulinas. Dissertação de Mestrado. Universidade Estadual Paulista Julio de Mesquita Filho, Jaboticabal. 56p.

Cruz CD, Regazzi AJ \& Carneiro PCS (2004) Modelos biométricos aplicados ao melhoramento genético. Viçosa, UFV. 480p.

Fernandes FT \& Oliveira E (1997) Principais doenças da cultura do milho. Sete Lagoas, Embrapa/CNPMS. 80p. (Circular Técnica, 26).

Ferreira DF (2000) SISVAR: Sistema de Análise de Variância, Versão 3.04, Lavras/DEX.
Gomes FP (1990) Curso de estatística experimental. Piracicaba, Nobel. 468p.

Juliatti FC, Appelt CCNS, Brito CH, Gomes LS, Brandão AM, Hamawaki OT \& Melo B (2004) Controle da feosféria, ferrugem comum e cercosporiose pelo uso da resistência genética, fungicidas e épocas de aplicação na cultura do milho. Bioscience Journal, 20:45-54.

Juliatti FC, Zuza JLMF, Souza PP \& Polizel AC (2007) Efeito do genótipo de milho e da aplicação foliar de fungicidas na incidência de grãos ardidos. Bioscience Journal, 23:34-41.

Mendes MC (2009) Micotoxinas, aspectos químicos e bioquímicos relacionados a grãos ardidos em híbridos de milho. Tese de Doutorado. Universidade Federal de Lavras, Lavras. 106p.

Paccola-Meirelles LD, Ferreira AS, Meirelles WF, Marriel IE \& Casela CR (2001) Detection of a bacterium associated with a leaf spot disease of maize in Brazil. Journal of Phytopathology, 149:275-279.

Pereira AOP, Camargo RV \& Camargo LEA (2005) Doenças do milho (Zea mays) In: Kimati H, Amorim L, Bergamim Filho A \& Camargo LEA (Eds.) Manual de fitopatologia: doenças de plantas cultivadas. Piracicaba, Ceres. p.477-488.

Pinho RG Von, Ramalho MAP, Resende IC, Silva HP \& Pozar G (2001) Reação de híbridos comerciais de milho às ferrugens polissora e tropical. Pesquisa Agropecuária Brasileira, 36:439445 .

Pozar G, Butruille D, Diniz HS \& Viglioni JP (2009) Mapping and validation of quantitative trait loci for resistance to cercospora infection in tropical maize (Zea mays L.). Theoretical and Applied Genetics, 118:553-564.

SAS Institute Inc. (1993) Statistical Analysis System user's guide. Cary, Statistical Analysis System Institute.

Shanner G \& Finney RE (1977) The effect of nitrogen fertilization on the expression of slow-mildewing resistance in knox wheat. Phytopathology, 70:1183-1186.

Souza PP (2005) Evolução da cercosporiose e da mancha-branca do milho e quantificação de perdas, em diferentes genótipos com controle químico. Dissertação de Mestrado. Universidade Federal de Uberlândia, Uberlândia. 77p.

Stell RG \& Torrie JK (1980) Principles and procedures of statistics: A biometrical approach. $2^{\mathrm{a}}$ ed. Tokyo, McGraw-Hill. 633p. 